\title{
Acral lentiginous melanoma: A retrospective study
}

\author{
Ugo Redi MD ${ }^{1}$ (D) | Giovanni Marruzzo MD ${ }^{1}$ (D) | Stefano Lovero MD $^{1}$ | \\ Hassan Tahir Khokhar MD ${ }^{2}$ | Federico Lo Torto MD ${ }^{1}$ | Diego Ribuffo MD
}

\author{
${ }^{1}$ Department of Surgery "Pietro Valdoni", \\ Plastic Surgery Unit, Sapienza University of \\ Rome, Rome, Italy \\ ${ }^{2}$ University of Medicine and Pharmacy \\ "Grigore T. Popa", lasi, Romania

\section{Correspondence} \\ Marruzzo Giovanni, Department of Surgery \\ "Pietro Valdoni" Plastic Surgery Unit, \\ Sapienza University of Rome, Rome, Italy. \\ Email: giovanni.marruzzo@uniroma1.it
}

\begin{abstract}
Background: Acral lentiginous melanoma (ALM) carries one of the worst prognoses among other subtypes. This malignant tumor is found on the distal limbs and is usually detected at late stages. Hereby, the authors present their experience on this melanoma subtype.

Methods: A retrospective study was conducted. Data were extracted from patients' medical records and from phone interviews.

Results: A total of 43 patients were included in the study. The main signs and symptoms disclosed by the patients were bleeding (41.9\%), size greater than $6 \mathrm{~mm}(41.9 \%)$, change in size $(37.2 \%)$, change in shape $(30.2 \%)$, rise above the surface of the skin (27.9\%), change in color (20.9\%), irregular borders (16.3\%), and inflammation (16.3\%). The first healthcare professional consulted was a general practitioner or a dermatologist in the majority of cases (88.3\%). Only $44.2 \%$ of the patients were sent by their first physician for a biopsy, whereas $30.3 \%$ were sent by the 2 nd physician. 14 patients underwent biopsy within 1 month from the first appointment with a physician, while 20 patients within 3 months and 9 patients within 6 months. Only 7 patients sought medical attention in the first 3 months; 21 patients sought medical care between 3 months and one year from the appearance of the lesion, while the remaining 15 patients waited more than a year.

Conclusions: One of the major issues found in ALM is represented by the diagnostic delay; this may be due to either the patients or the physicians' failure to recognize warning signs.
\end{abstract}

KEYWORDS

acral lentiginous melanoma, clinical presentation, diagnostic delay

\section{1 | INTRODUCTION}

Melanoma is a malignant tumor that originates from the melanocytes, primarily involving the skin. Its incidence is rising worldwide in the white population, especially in those areas where fair-skinned peoples receive excessive sun exposure. ${ }^{1}$

The incidence of cutaneous melanoma has increased at rapid rate during the last 50 years, much higher than any other cancer in the world, with an estimated 91270 new cases in 2018 only in the United States. $^{2}$

Such alarming epidemiological data show that melanoma is a major public health problem and it requires further attention.

The principal clinical and histological melanomas' subtypes are as follows: superficial spreading melanoma, lentigo maligna melanoma, nodular melanoma, and acral lentiginous melanoma (ALM). ${ }^{1}$ Despite being the least common of the four major subtypes, it has been reported that $7 \%$ of all cutaneous melanomas are located at acral 
sites, ${ }^{1}$ and ALM is the most prevalent subtype in these locations, typically occurring on the palms, soles, and nail beds. ${ }^{3,4}$ (Figure 1). Clinically, in the early stage it presents as an irregular, poorly circumscribed pigmented region, and later on, a nodular area reflects the invasive growth pattern. In the non-Caucasian population, this subtype of melanoma occurs with a higher proportion than other subtypes. ${ }^{5}$ The incidence rate of this tumor appears to be correlated with increasing age. ${ }^{6}$

The onset of ALM occurs primarily in people aged between 59 and 63 years old, generally later when compared to other subtypes, with the highest incidence in the seventh decade of life.,8

ALMs and nodular melanomas are usually diagnosed at later stages and have traditionally been associated with a worse prognosis compared to the other histologic subtypes of the extremities. ${ }^{8,9}$

Nail ALM patients seem to have shorter survival rates when compared to non-nail ALM. ${ }^{6,10}$

A recent study by Fujisawa et al confuted this theory and showed how ALM is not associated with a survival disadvantage, except for stage III. $^{8,11}$

The various theories that have been suggested to describe the more malignant tendency of this carcinoma include the relatively more aggressive biological behavior of ALMs and the lack of patient's awareness as the tumor can grow in regions that are normally covered, such as under the nails or on palms and soles. ${ }^{8}$

Early detection of ALM can be difficult and requires the combination of clinical as well as dermoscopic, histopathologic, and molecular findings. ${ }^{12}$

Dermoscopy, in particular, is widely recognized as the best examination method to early diagnose ALM, providing an extremely useful tool to obtain diagnostic accuracy. As a matter of fact, it is quite common for ALM to be misdiagnosed as mycosis, warts, diabetic ulcers, or lesions of other nature. Besides, due to its location, a suspected ALM can be technically challenging to biopsy. ${ }^{13}$

The aim of this study was to describe our experience on ALM.

\section{2 | METHODS}

We conducted a retrospective study of patients with the histological diagnosis of ALM according to the pathology report, registered in the cutaneous melanoma database of "Policlinico Umberto I" University Hospital, Rome, Italy. Data were extracted from patients' medical records as well as from a telephone survey.

A total of 802 patients were diagnosed and treated for a cutaneous melanoma by the Plastic and Reconstructive Surgery Department between January 1996 and December 2017. Out of the total number of patients, 751 were excluded from the study because they were affected by melanoma that did not develop in the acral sites. 8 of the remaining 51 patients were not enrolled in the study because their lesions belonged to a different histological type (Superficial Spreading Melanoma). Our study included a total of 43 cases ( 23 males and 20 females) with histological diagnosis of ALM between 38 and 84 years of age.
A sentinel lymph node biopsy (SLNB) was performed in 35 of these 43 melanomas because they measured $>1 \mathrm{~mm}$ according to Breslow thickness.

A telephonic questionnaire was conducted directed toward patients diagnosed with ALM or their close relatives, concerning the clinical course of the tumor, the patient's reason for seeking care, diagnostic delay, and signs and symptoms. This survey supported the data extraction from medical records.

Regarding the lesion's clinical progression, the following information has been asked: site of the tumor, if a previous lesion was present at the same area (none, congenital, lifelong lesion that transformed into ALM, noncongenital lesions that have been present for years), and whether the patient had any previous burns or other injuries at the melanoma's site (none, minor, serious). Data concerning the purpose for pursuing care included the first person who detected the lesion (patient, physician, other), if the primary reason the patient turned to the physician was the lesion, the total sum of healthcare professionals the patient visited including their specialties, and antecedent diagnosis. Another important question included in the questionnaire was regarding the first physician who advised the performance of an excisional biopsy. Signs and symptoms listed in the $A B C D E s$ of skin tumors ${ }^{14}$ were also included in the telephone questionnaire. The delay caused by the patient has been delineated as time between first recognition of the lesion and first visit to a physician, whereas the time between the first appointment with a physician and the date of the biopsy procedure has been stated as medical delay. The following intervals were assigned to the delays: $\leq 1$ month, $>1$ month, $\leq 3$ months, $>3$ months $\leq 6$ months, $>6$ months $\leq 1$ year, and $>1$ year.

\section{3 | RESULTS}

From 1996 to 2017, the Plastic Surgery Department of "Policlinico Umberto I" University Hospital, a total of 43

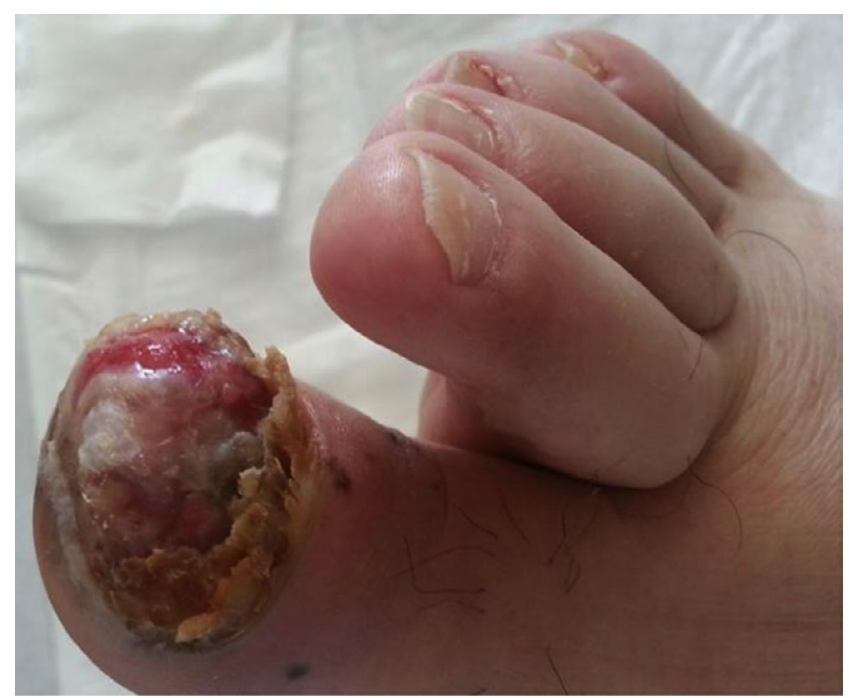

FIGURE 1 Clinical presentation of sub-nail ALM 
TABLE 1 Sites of acral lentiginous melanomas in the series

\begin{tabular}{|c|c|c|c|c|c|c|c|c|c|}
\hline \multirow[b]{2}{*}{ Patients } & \multicolumn{4}{|c|}{ Hand } & \multicolumn{4}{|c|}{ Foot } & \multirow{2}{*}{$\begin{array}{l}\text { Sub- } \\
\text { nail }\end{array}$} \\
\hline & Left & Right & Palm & Dorsum & Left & Right & Plant & Dorsum & \\
\hline 1 & & & & & $x$ & & & $x$ & \\
\hline 2 & & & & & $x$ & & $x$ & & \\
\hline 3 & & $x$ & & & & & & & $x$ \\
\hline 4 & $x$ & & & & & & & & $x$ \\
\hline 5 & & $x$ & $x$ & & & & & & \\
\hline 6 & & $x$ & & $x$ & & & & & \\
\hline 7 & & & & & & $x$ & & & $x$ \\
\hline 8 & & & & & & $x$ & & & $x$ \\
\hline 9 & & & & & $x$ & & & $x$ & \\
\hline 10 & & & & & & $x$ & $x$ & & \\
\hline 11 & $x$ & & & $x$ & & & & & \\
\hline 12 & & & & & $x$ & & & & $x$ \\
\hline 13 & $x$ & & $x$ & & & & & & \\
\hline 14 & & $x$ & & $x$ & & & & & \\
\hline 15 & & & & & & $x$ & & $x$ & \\
\hline 16 & & & & & $x$ & & $x$ & & \\
\hline 17 & & $x$ & & $x$ & & & & & \\
\hline 18 & & $x$ & & & & & & & $x$ \\
\hline 19 & $x$ & & $x$ & & & & & & \\
\hline 20 & & & & & & $x$ & & $x$ & \\
\hline 21 & $x$ & & & $x$ & & & & & \\
\hline 22 & & & & & $x$ & & & & $x$ \\
\hline 23 & & $x$ & & $x$ & & & & & \\
\hline 24 & & & & & & $x$ & & $x$ & \\
\hline 25 & & & & & $x$ & & $x$ & & \\
\hline 26 & & $x$ & $x$ & & & & & & \\
\hline 27 & & & & & $x$ & & $x$ & & \\
\hline 28 & $x$ & & & & & & & & $x$ \\
\hline 29 & & & & & & $x$ & $x$ & & \\
\hline 30 & & & & & & $x$ & $x$ & & \\
\hline 31 & & & & & $x$ & & & $x$ & \\
\hline 32 & & & & & & $x$ & & & $x$ \\
\hline 33 & & & & & $x$ & & $x$ & & \\
\hline 34 & & & & & $x$ & & $x$ & & \\
\hline 35 & & & & & & $x$ & & $x$ & \\
\hline 36 & & & & & & $x$ & & & $x$ \\
\hline 37 & & & & & $x$ & & & & $x$ \\
\hline 38 & & & & & & $x$ & & $x$ & \\
\hline 39 & & & & & $x$ & & $x$ & & \\
\hline 40 & & $x$ & & & & & & & $x$ \\
\hline 41 & & & & & $x$ & & $x$ & & \\
\hline 42 & & $x$ & & $x$ & & & & & \\
\hline 43 & & & & & $x$ & & & $x$ & \\
\hline Total & 6 & 10 & 4 & 7 & 15 & 12 & 11 & 9 & 12 \\
\hline
\end{tabular}


patients were detected with ALM. Of these patients, 23 were men (53.5\%) and 20 were women (46.5\%). Data were collected mainly from patients' medical records. A telephone survey was also carried out.

Overall, 35 patients took part in the telephone survey. The remaining could not participate because 5 of them were dead at the time of the telephone survey, while the other 3 had an underlying disease (1 patient had a stroke and 2 suffered of dementia). However, in these cases a close relative of the patient was interviewed. The lesions were located on the foot in 27 patients (62.8\%) and on the hand in 16 patients (37.2\%). Out of the total number, 12 ALM presented in the subungual region, 7 were located on the feet and 5 on the hands (Table 1). There was not any significant predominance of one limb over the contralateral one.

The signs and symptoms disclosed by the 43 patients (Figure 2), in order of frequency, were as follows:

- Bleeding 18 patients (41.9\%)

- Size greater than $6 \mathrm{~mm}$ by 18 patients (41.9\%)

- Change in size by 16 patients (37.2\%)

- Change in shape by 13 patients (30.2\%)

- Rise above the surface of the skin by 12 patients (27.9\%)

- Change in color by 9 patients $(20.9 \%)$

- Irregular borders by 7 patients (16.3\%)

- Inflammation by 7 patients (16.3\%)

- More than 2 colors by 6 patients (13.9\%)

- Itching by 5 patients (11.6\%)

- Pain by 4 patients (9.3\%)

- Asymmetry by 4 patients $(9.3 \%)$

- Nail dystrophy by 3 patients (6.9\% of the total number of our patients, $25 \%$ of only sub-nail melanoma patients)

- Fatigue by 2 patients (4.6\%)

- Swollen lymph glands by 2 patients (4.6\%)

- Night sweats for several months by 1 patient (2.3\%)

By order of frequency, the first healthcare professional consulted was a general practitioner in 25 cases (58.1\%), a dermatologist in 13 cases (30.2\%), a podiatrist in 4 cases (9.3\%), and another specialist in 1 case $(2.3 \%)$ (Figure 3 ).
The patients had multiple visits to numerous physicians, and Figure 4 displays how many different healthcare workers had to been seen by patients before having a diagnosis of ALM. In other words, it shows the time necessary for the patients to be referred for a biopsy after engaging with the healthcare system. The earlier the referral was made, the earlier the correct diagnosis would have been made. As it is evident from the graph, only $44.2 \%$ of the patients were sent by their first physician for a biopsy, whereas $30.3 \%$ were sent by the 2 nd physician. This deferment in referral could explain the diagnostic delay caused by the physicians.

In regard to the delay caused by patients, only 7 of them (16.3\%) turned to the physician in the first 3 months; 21 patients (48.8\%) sought medical care between 3 months and one year from the appearance of the lesion, while the remaining 15 patients (34.9\%) waited more than a year.

With regard to the medical delay, 14 patients (32.5\%) underwent biopsy within 1 month from the first appointment with a physician, while 20 patients $(46.5 \%)$ within 3 months and 9 patients $(21 \%)$ within 6 months.

The SLNB ${ }^{15,16}$ has been performed only in patients with a Breslow's thickness $>1 \mathrm{~mm}$ (35 patients). The results from the SLN biopsy were negative in 22 patients (62.9\%) and positive in 13 patients (37.1\%).

The median age on excision of these patients was 68 years, ranging from 38 to 84 years old. 35 of 43 acral melanoma were $>1 \mathrm{~mm}$ of thickness, especially 9 with a Breslow score $>2 \mathrm{~mm}$ and 11 with a Breslow score $>4 \mathrm{~mm}$. The mean (SD) tumor thickness was $2.80 \mathrm{~mm}$, and the median thickness was $2.40 \mathrm{~mm}$, ranging from 0.7 to $6 \mathrm{~mm}$.

An important observation was that the majority of the patients could not recall if any previous lesions had been detected at the same site of the ALM. Only $7 \%$ of the total number of patients (3) provided such information: 1 case reported that the tumor had developed over a congenital lesion that was present by birth, 1 patient recalled a persistent lesion, and 1 patient claimed to have a lesion for 10 years. None of the patients remembered burns at the same location as the tumor; however, five patients (11.6\%) recalled a significant injury.

Four patients (9.3\%) visited a podiatrist for an evaluation of a different injury; the podiatrist on the other hand diagnosed the lesion

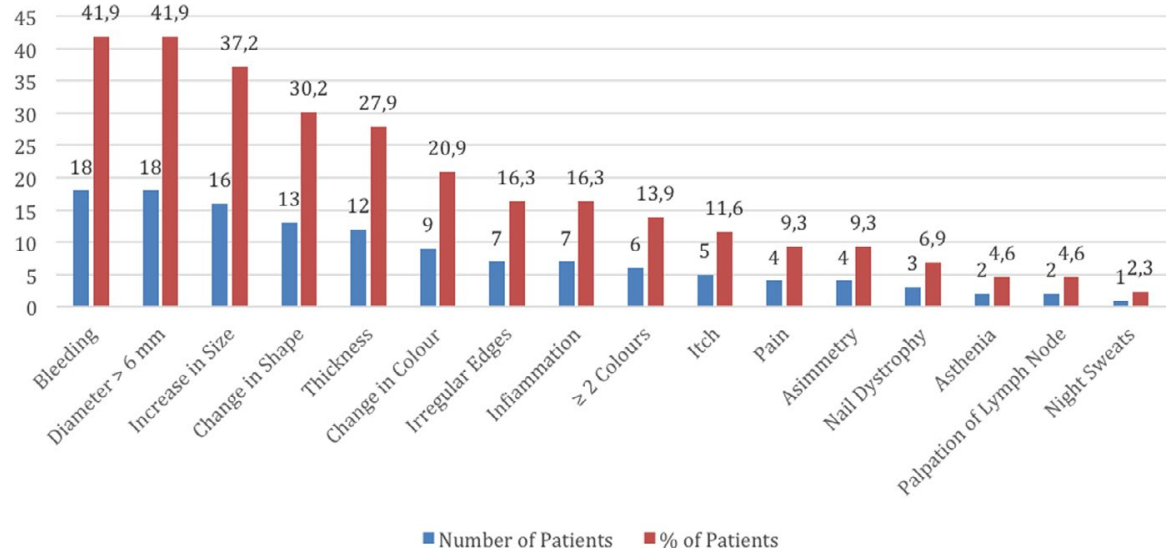

- Number of Patients $\quad$ m of Patients
FIGURE 2 Signs and symptoms reported by patients 
FIGURE 3 First healthcare professionals consulted by patients
FIGURE 4 Diagnostic delay time elapsed until biopsy

FIGURE 5 (A) Clinical presentation of ALM on the palm of the left hand. (B) Dermoscopy shows a parallel ridge pattern with asymmetric distribution of pigment

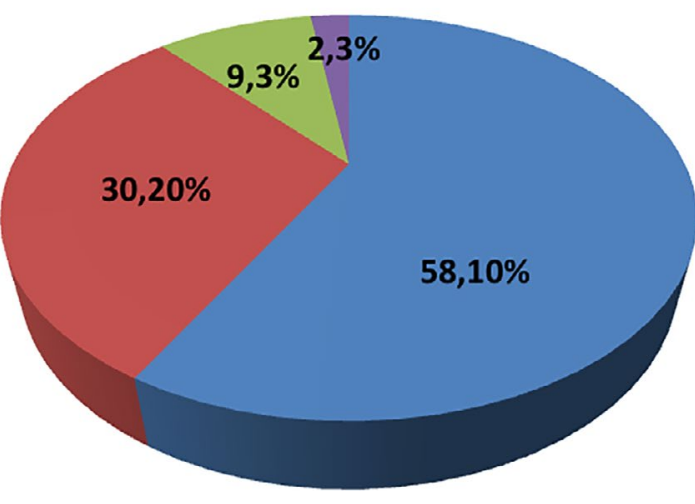

General Practitioner

Dermatologist

Podiatrist

Other Medical Specialist

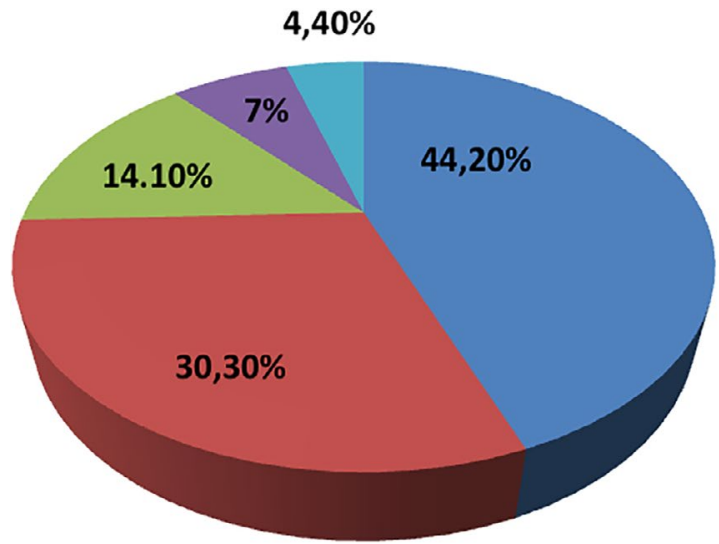

First Health Worker

Second Health Worker

$\square$ Third Health worker

Fourth Health Worker

$\square$ Fifth Health Worker

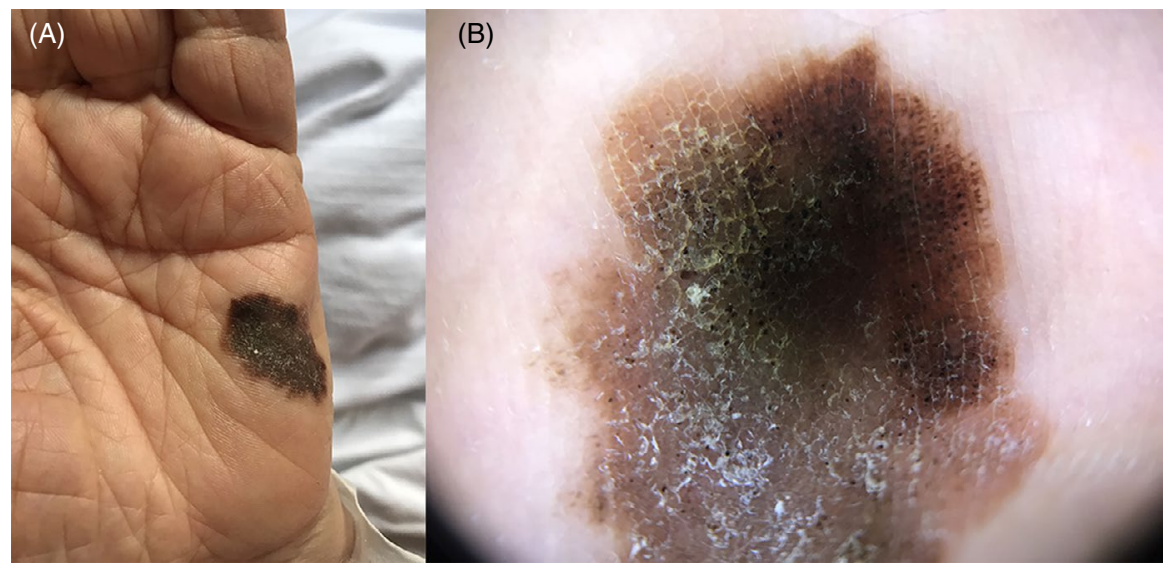

and advised the patient to see a dermatologist. Moreover, even though the lesion was detected by the patients themselves in $70 \%$ of the cases, the indication of consulting a specialist was introduced by a friend or a relative in $35 \%$ of those cases.

\section{4 | DISCUSSION}

Some authors refer to ALM as the subtype of melanoma that arise exclusively on glabrous skin of the palms, soles or nail unit. Other authors include melanomas from dorsal surfaces of the hands and feet in this group. ${ }^{17}$

Many authors use the terms ALM and acral melanoma as synonyms. More precisely, ALM is the most common histopathological type of melanoma that arises at acral sites but not the only one. Acral melanoma includes other subtypes of melanoma that can arise in these locations. For instance, the nodular or superficial spreading subtypes may occur in these areas, especially on the dorsum of the hands or feet. ${ }^{18}$

In the present study, ALM was most commonly found on the foot and the subungual region was mostly affected. The first toe or the first finger was most commonly involved. These tumors were often located on weight-bearing surfaces, confirming that pressure may play an important role in pathogenesis, as it may be associated with heat or repeated trauma., 19-22 (Figures 5-7).

Our finding is analogous with a previous study, where $82 \%$ of ALMs were described on the foot, ${ }^{23}$ but the hand is more often the location for subungual tumors, according to various other studies. ${ }^{3,23-25}$ 
Soon et $\mathrm{al}^{22}$ found that $33.96 \%$ had previously been incorrectly diagnosed; $60 \%$ of the misdiagnoses were amelanotic and $40 \%$ replicated benign hyperkeratotic lesions. Pain and bleeding were the only signs and symptoms that triggered an urge to consult a specialist for at least half of the patients in the study. Nonetheless, in the general population, color, bleeding, and variation in dimensions were the main reasons patients pursued a specialist's advice. ${ }^{26,27}$ Remarkably, only $30.2 \%$ of the patients consulted a dermatologist first, whereas more than half (58.1\%) first saw a general practitioner, and very few $(9.3 \%)$ saw a podiatrist. Dermatologists suspected a malignant lesion more often than podiatrists or family practitioners. This outcome emphasizes the crucial role that some healthcare professionals such as the podiatrists can possibly play in detecting ALMs early in the disease process. Furthermore, an imperative observation was that although a large number of patients (70\%) noticed the lesion themselves, about half of them (35\%) decided to seek a specialist's advice, only after being encouraged or suggested by friends or relatives. This observation is also consistent with the literature. Richard et $a^{28,29}$ mention that most malignant melanoma lesions were noticed by the patient themselves or a family member; moreover, the individual who identified the lesion also encouraged seeking of a medical care in $50 \%$ of the cases which is slightly higher compared to our study. Another impressive finding was that the awareness to pursue medical care came mostly from women

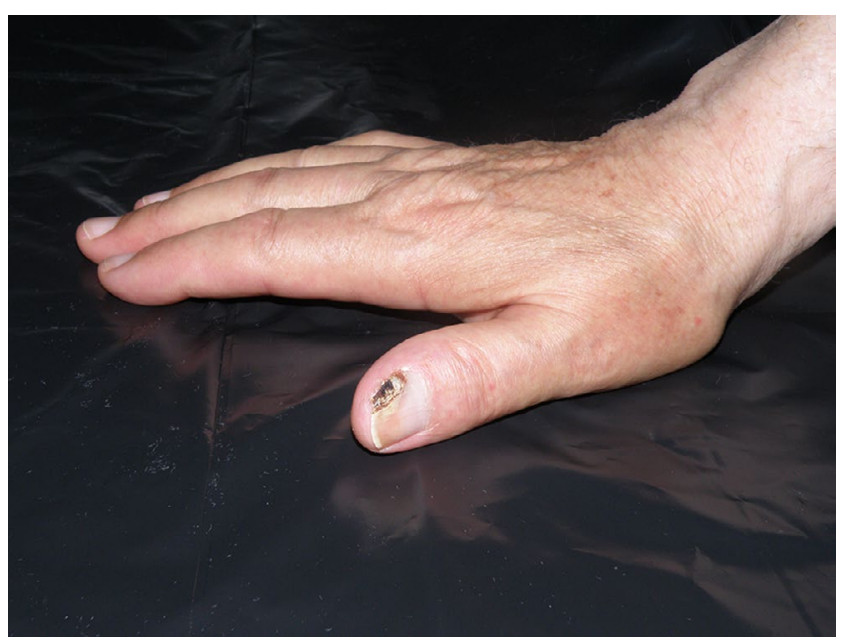

FIGURE 6 Clinical presentation of subungual ALM of the thumb (whether patients themselves or relatives). In these studies, and also in our study, women identified malignant melanoma more regularly than men, who also usually necessitated the advice of a friend or of another physician for consulting a specialist. ${ }^{28,29}$

The average time between the patient's encounter of a lesion and the suspicion that the lesion is worthy of an evaluation by the physician was 18 months, and the average delay between this suspicion and the actual consultation by a medical doctor was 2 months. Substantially, the studies of Richards et $\mathrm{al}^{28,29}$ found that despite the existence of media operation to promote prevention, $25 \%$ of the patients believed that removing a tumor was dangerous, only $24.8 \%$ were conscious about the gravity of melanoma, and others just assumed that a lesion could not be malignant if asymptomatic. The signs and symptoms that encouraged a fast consultation of a healthcare professional were the late ones, such as bleeding, whereas observing the standard $A B C D E$ signs led to delay in seeking medical attention. ${ }^{30,31,48-53}$

Boriani et $\mathrm{al}^{32}$ showed that higher aggressiveness of ALM is due to the diagnostic delay and the more advanced thickness at diagnosis.

Diagnostic delays caused by the patients and the physicians are both significant. ${ }^{33-41}$ Even though the signs and symptoms listed in $A B C D E$ and 7-point Glasgow often refer to the palms and soles, the delay in diagnosis is commonly encountered because ALM tumors can present with clinical diversity and are not just limited to these locations.

Our study was limited by being a single-center study with a limited number of patients, being this tumor not so common in the Caucasian population. ${ }^{42-44}$

Moreover, data were gathered in a retrospective manner from a small sample by a medical chart review and a telephone survey, during which patients or close relatives had to recall events happened in the past. Nonetheless, the data presented on ALMs are impressive and generally consistent with those described in the literature.

\section{CONCLUSION}

Our findings conclusively highlight the failure of health campaigns that are hosted to raise awareness of malignant melanoma in the population for a number of reasons: knowledge of the ABCDEs and

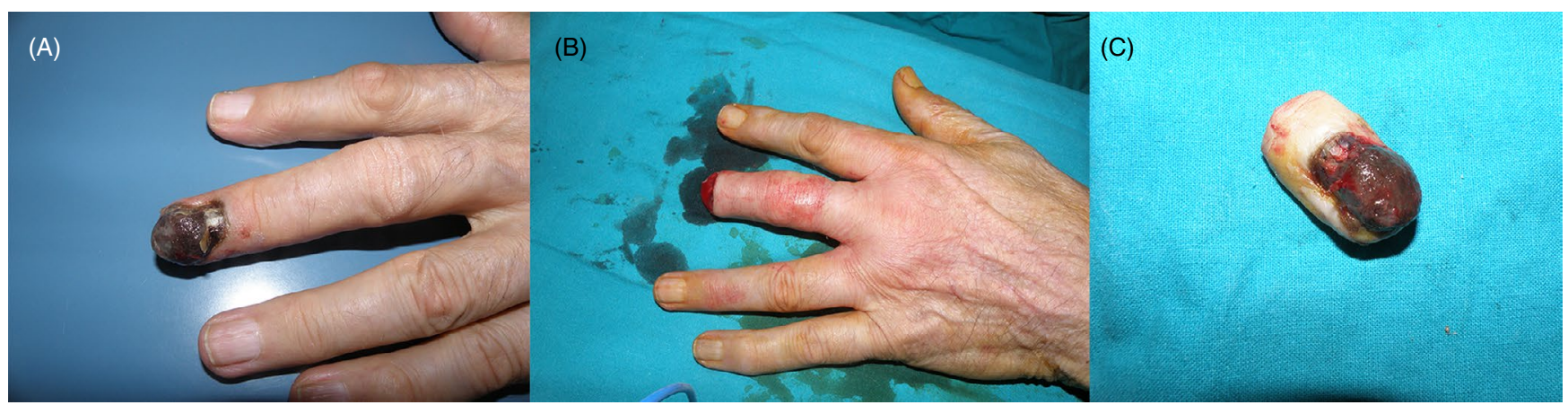

FIGURE 7 (A) Clinical presentation of subungual ALM of the middle finger. (B, C) Intraoperative view after amputation of the distal phalanx of the middle finger 
Glasgow 7-point criteria is still poor, and acral areas are not understood to be possible sites of malignant melanoma in the general population. Information about subungual melanoma is not successfully reaching the public.

Interestingly, mass media campaigns in Australia and in other countries reportedly achieved good results in terms of behavioral changes. ${ }^{45-47}$

In addition to this, family physicians and podiatrists need further training with respect to melanoma because they may determine a better prognosis due to an early diagnosis. Furthermore, our article analytically describes the clinical presentation of this rare tumor as perceived by patients.

\section{AUTHOR CONTRIBUTIONS}

RU, MG, LS, KHT, LTF, and RD all contributed to writing, reviewing, and analysis. RU and MG contributed to the clinical discussion.

\section{DATA AVAILABILITY STATEMENT}

The data that support the findings of this study are available from the corresponding author upon reasonable request. Note: There is no data citation available for the reference list nor public link to access the data.

\section{ORCID}

Ugo Redi (iD https://orcid.org/0000-0003-0136-4263

Giovanni Marruzzo iD https://orcid.org/0000-0002-6546-8881

\section{REFERENCES}

1. Thompson JF, Scolyer RA, Kefford RF. Cutaneous melanoma. Lancet. 2005;365:687-701.

2. American Cancer Society. Cancer Facts \& Figures 2018. Anlanta, GA: American Cancer Society; 2018.

3. Kuchelmeister C, Schaumburg-Lever G, Garbe C. Acral cutaneous melanoma in caucasians: clinical features, histopathology and prognosis in 112 patients. Br J Dermatol. 2000;143:275-280.

4. de Giorgi V, Rossari S, Gori A, et al. The prognostic impact of the anatomical sites in the head and neck melanoma': scalp versus face and neck. Melanoma Res. 2012;22(5):402-405.

5. Stalkup JR, Orengo IF, Katta R. Controversies in acral lentiginous melanoma. Dermatol Surg. 2002;28:1051-1059.

6. Huang K, Fan J, Misra S. Acral lentiginous melanoma: incidence and survival in the United States, 2006-2015, an analysis of the SEER registry. J Surg Res. 2020;251:329-339. https://doi.org/10.1016/j.jss.2020.02.010

7. Phan A, Touzet S, Dalle S, Ronger-Savle S, Balme B, Thomas L. Acral lentiginous melanoma: a clinicoprognostic study of 126 cases. $\mathrm{Br} J$ Dermatol. 2006;155:561-569.

8. Fujisawa Y, Yoshikawa S, Minagawa A, et al. Clinical and histopathological characteristics and survival analysis of 4594 Japanese patients with melanoma. Cancer Med. 2019;8(5):2146-2156.

9. Pereda C, Traves V, Requena C, et al. Clinical presentation of acral lentiginous melanoma: a descriptive study. Actas Dermosifiliogr. 2013;104(3):220-226

10. Howard M, Xie C, Wee E, et al. Acral lentiginous melanoma: clinicopathologic and survival differences according to tumour location. Australas J Dermatol. 2020 May 3. https://doi.org/10.1111/ ajd.13310. Epub ahead of print

11. Egger ME, McMasters KM, Callender GG, et al. Unique prognostic factors in acral lentiginous melanoma. Am J Surg. 2012;204(6):874-879.
12. Darmawan CC, Jo G, Montenegro SE, et al. Early detection of acral melanoma: a review of clinical, dermoscopic, histopathologic, and molecular characteristics. J Am Acad Dermatol. 2019;81(3):805-812. https://doi.org/10.1016/j.jaad.2019.01.081

13. Huayllani MT, Restrepo DJ, Boczar D, et al. National comprehensive analysis of characteristics of acral lentiginous melanoma. Anticancer Res. 2020;40(6):3411-3415. https://doi.org/10.21873/ anticanres.14325

14. Abbasi NR, Shaw HM, Rigel DS, et al. Early diagnosis of cutaneous melanoma: revisiting the $A B C D$ criteria. JAMA. 2004;292:2771-2776.

15. Penzer R, Ersser SJ. Principles of Skin Care: A Guide for Nurses and Other Health Care Professionals. : Wiley-Blackwell; 2010.

16. Castaneda CA, Torres-Cabala C, Castillo M, et al. Tumor infiltrating lymphocytes in acral lentiginous melanoma: a study of a large cohort of cases from Latin America. Clin Trans Oncol. 2017;19(12):1478-1488.

17. Haugh AM, Zhang B, Quan VL, et al. Distinct patterns of acral melanoma based on site and relative sun exposure. J Invest Dermatol. 2018;138(2):384-393. https://doi.org/10.1016/j.jid.2017.08.022

18. Basurto-Lozada P, Molina-Aguilar C, Castañeda-Garcia C, et al. Acral lentiginous melanoma: basic facts, biological characteristics and research perspectives of an understudied disease. Pigment Cell Melanoma Res. 2020 Apr 24. https://doi.org/10.1111/pcmr.12885. [Epub ahead of print]

19. Minagawa A, Toshikazu O, Okuyama R. Melanomas and mechanical stress points on the plantar surface of the foot. N Eng J Med. 374(24):2404-2406

20. Costello CM, Pittelkow MR, Mangold AR. Acral melanoma and mechanical stress on the plantar surface of the foot. N Engl J Med. 2017;377(4):395-396.

21. Namiki T, Coelho SG, Hearing VJ. NUAK2: an emerging acral melanoma oncogene. Oncotarget. 2011;2:695-704.

22. Soon SL, Solomon Jr AR, Papadopoulos D, Murray DR, McAlpine $B$, Washington CV. Acral lentiginous melanoma mimicking benign disease: the Emory experience. J Am Acad Dermatol. 2003;48:183-188.

23. O'Leary JA, Berend KR, Johnson JL, Levin LS, Seigler HF. Subungual melanoma: a review of 93 cases with identification of prognostic variables. Clin Orthop Relat Res. 2000;378:206-212.

24. Banfield CC, Redburn JC, Dawber RP. The incidence and prognosis of nail apparatus melanoma. A retrospective study of 105 patients in four English regions. Br J Dermatol. 1998;139:276-279.

25. Takeshi M, Jeong-Hun K. Chapter 18 Biomarkers for Melanoma Diagnosis and the Technologies Used to Identify Them. Breakthroughs in Melanoma Research. London: InTech; 2011. .

26. Massi D, Pinzani P, Simi L, et al. BRAF and KIT somatic mutations are present in amelanotic melanoma. Melanoma Res. 2013;23(5):414-419.

27. Daryanani D, Plukker JT, De Hullu JA, Kuiper H, Nap RE, Hoekstra HJ. Pregnancy and early-stage melanoma. Cancer. 2003;97(9):2248-2253.

28. Richard MA, Grob JJ, Avril MF, et al. Delays in diagnosis and melanoma prognosis (ii): the role of doctors. Int J Cancer. 2000;89:280-285

29. Richard MA, Grob JJ, Avril MF, et al. Delays in diagnosis and melanoma prognosis (i): the role of patients. Int J Cancer. 2000;89:271-279.

30. Bañuls J. Strategies for reducing diagnostic delay in acral lentiginous melanoma. Actas Dermosifiliogr. 2018;109(9):764.

31. Huayllani MT, Sisti A, Restrepo DJ, et al. Desmoplastic melanoma: clinical characteristics and survival in the US population. Cureus. 2019;11(6):e4931. https://doi.org/10.7759/cureus.4931

32. Boriani F, O'Leary F, Tohill M, Orlando A. Acral Lentiginous Melanoma - misdiagnosis, referral delay and 5 years specific survival according to site. Eur Rev Med Pharmacol Sci. 2014;18(14):1990-1996. 
33. Cuomo R, Nisi G, Brandi C, Grimaldi L. Surgical implications of ischemia reperfusion damage and future perspectives. J Invest Surg. 2019;19:1-2.

34. Cuomo R, Sisti A, Grimaldi L, Nisi G, Brandi C, D'Aniello C. Ischemic damage of the flaps: new treatments. J Invest Surg. 2020;33(2):189-190.

35. Cuomo R, Grimaldi L, Brandi C, Nisi G, D'Aniello C. Skin graft donor site: a procedure for a faster healing. Acta Biomed. 2017;88(3):310-314.

36. Sisti A, Tassinari J, Milonia L, Grimaldi L, Nisi G. Limberg flap for surgical treatment of melanoma. Plast Reconstr Surg. 2016;138(3):e565 -e566.

37. Oliver JD, Boczar D, Sisti A, et al. National analysis of patients with external ear melanoma in the United States. J Craniofac Surg. 2019;30(8):e787-e790.

38. Huayllani MT, Bagaria SP, Restrepo DJ, et al. Residual tumor on wide excisional margins after treatment of invasive melanoma. Anticancer Res. 2020;40(2):1059-1063.

39. Restrepo DJ, Huayllani MT, Boczar D, et al. Biopsy type disparities in patients with melanoma: who receives the standard of care? Anticancer Res. 2019;39(11):6359-6363.

40. Boczar D, Sisti A, Restrepo DJ, et al. National analysis of patients with ulcerated melanoma in the United States. Anticancer Res. 2020;40(2):1055-1058.

41. Huayllani MT, Bagaria SP, Restrepo DJ, et al. Wide excisional surgery in invasive melanoma treatment: factors driving non-compliance with national guidelines. Anticancer Res. 2020;40(2):1065-1069.

42. Behbahani S, Malerba S, Samie FH. Acral lentiginous melanoma: clinicopathologic characteristics and survival outcomes in the United States National Cancer Database 2004-2016. Br J Dermatol. 2020 May 14. https://doi.org/10.1111/bjd.19211. [Epub ahead of print]

43. Wee E, Wolfe R, Mclean C, Kelly JW, Pan Y. The anatomic distribution of cutaneous melanoma: a detailed study of 5141 lesions. Australas J Dermatol. 2020;61(2):125-133. https://doi.org/10.1111/ ajd.13223

44. Lobl MB, Santos C, Clarey D, et al. Treatments and associated outcomes of acral lentiginous melanoma: a review. J Am Acad Dermatol. 2019 Nov 15:S0190-9622(19)33111-1. https://doi.org/10.1016/j. jaad.2019.11.021. [Epub ahead of print]
45. Apalla Z, Lallas A, Sotiriou E, Lazaridou E, loannides D. Epidemiological trends in skin cancer. Dermatol Pract Concept. 2017;7(2):1-6. https://doi.org/10.5826/dpc.0702a01

46. Broly M, Drak Alsibai K, Cenciu B, et al. Clinical and histological characteristics, and management of melanoma in French Guiana, 2007-2018. Int J Dermatol. 2020;59(8):997-999. https://doi. org/10.1111/ijd.14961

47. Yu Z, Dee EC, Nambudiri VE, Ogbechie-Godec OA, Jakus J, Siegel DM. Quality and readability of online health information for acral lentiginous melanoma. Dermatol Surg. 2020 May 29. https://doi. org/10.1097/DSS.0000000000002457. [Epub ahead of print]

48. Sisti A, Fallaha A, Tassinari J, Nisi G, Grimaldi L, Eisendle K. Melanoma in situ mimicking a Lichen planus-like keratosis. Acta Biomed. 2018;88(4):496-498.

49. Oliver JD, Boczar D, Sisti A, et al. Eyelid melanoma in the United States: a National Cancer Database analysis. J Craniofac Surg. 2019;30(8):2412-2415.

50. Sisti A, Sisti G, Oranges CM. Topical treatment of melanoma skin metastases with imiquimod: a review. Dermatol Online J. 2014;21(2):13030/qt8rj4k7r6.

51. Catalano C, De Magnis A, Kanninen T, et al. Vulvar melanoma: a 33 years single Italian center experience. G Ital Dermatol Venereol. 2015;150(3):277-282.

52. Boczar D, Restrepo DJ, Sisti A, et al. Disparity on unplanned readmission in melanoma patients: a National Cancer Database analysis. Anticancer Res. 2019;39(12):6877-6880.

53. Boczar D, Restrepo DJ, Sisti A, et al. Analysis of melanoma in African American patients in the United States. Anticancer Res. 2019;39(11):6333-6337. https://doi.org/10.21873/antic anres.13844

How to cite this article: Redi U, Marruzzo G, Lovero S, Khokhar HT, Lo Torto F, Ribuffo D. Acral lentiginous melanoma: A retrospective study. J Cosmet Dermatol 2020;00:1-8. https://doi.org/10.1111/jocd.13737 